\title{
The Conditions under Which Consolidation of Serial-Order Conditioned Fear Requires De Novo Protein Synthesis in the Basolateral Amygdala Complex
}

\author{
๑Matthew J. Williams-Spooner, R. Frederick Westbrook, and $₫$ Nathan M. Holmes \\ School of Psychology, University of New South Wales, Sydney, 2052 New South Wales, Australia
}

Consolidation of conditioned fear to a stimulus (S1) paired with shock requires de novo protein synthesis in the basolateral amygdala complex (BLA), whereas consolidation of conditioned fear to a stimulus (S2) paired with the fear-eliciting S1 requires DNA methylation but not de novo protein synthesis in the BLA. The present experiments merged these protocols by exposing rats to pairings of a serial S2-S1 compound and shock to examine if/when protein synthesis in the BLA is required to consolidate fear to S2. Rats received a BLA infusion of the protein synthesis inhibitor, cycloheximide, immediately after the S2-S1-shock session and were subsequently tested with S2. The infusion disrupted consolidation of fear to $S 2$ when there had been no prior training of $S 1$ (Experiment 1), the prior training had consisted of unpaired presentations of $S 1$ and shock (Experiment 4), or in pairings of $S 1$ and sucrose (Experiment 5). Consolidation of fear to $S 2$ was unaffected by the infusion of cycloheximide but was disrupted by the DNA methyltransferase inhibitor, 5-AZA, when S1 had been previously fear-conditioned (Experiments 2a, 2b, and 3). These findings imply that what has already been learned about $S 1$ determines the BLA processes that consolidate fear to S2. The already-fear-conditioned S1 blocks the S2-shock association that otherwise forms (and whose consolidation requires de novo protein synthesis in the BLA) while simultaneously acting as a learned source of danger for its S2 associate (whose consolidation requires DNA methylation but not de novo protein synthesis in the BLA).

Key words: amygdala; consolidation; fear; higher-order conditioning; memory; protein synthesis

Significance Statement

Protein synthesis is widely thought to be crucial for consolidating new learning into stable memories, including the consolidation of conditioned fear memories in the basolateral amygdala complex (BLA). However, our data provide clear evidence that the requirement for protein synthesis to consolidate conditioned fear in the BLA depends on an animal's previous training history, and the type of learning that is consolidated. Further, within the BLA, our data show that DNA methylation, and not protein synthesis, is necessary to consolidate higher-order conditioned fear, indicating that epigenetic mechanisms may provide a more fundamental mnemonic substrate.

\section{Introduction}

Laboratory rodents learn to fear cues that signal innate or learned sources of danger. A standard protocol to produce the former type of fear consists of pairing an affectively neutral stimulus (e.g., a sound, S1) and an aversive foot shock. The protocol used to produce the latter type of fear consists of first pairing S1 with

\footnotetext{
Received April 4, 2019; revised June 2, 2019; accepted July 14, 2019.

Author contributions: M.J.W.-S., R.F.W., and N.M.H. designed research; M.J.W.-S. performed research;M.J.W.-S. analyzed data; M.J.W.-S. wrote the first draft of the paper; M.J.W.-S., R.F.W., and N.M.H. edited the paper; M.J.W.S., R.F.W., and N.M.H. wrote the paper.

This work was supported by Australian Research Council Discovery Grant DP170103952 to N.M.H. and R.F.W., and Australian Government Research Training Fellowship to M.J.W.-S

The authors declare no competing financial interests.

Correspondence should be addressed to Nathan M. Holmes at n.holmes@unsw.edu.au.

https://doi.org/10.1523/JNEUROSCI.0768-19.2019

Copyright $\odot 2019$ the authors
}

shock, and then pairing a second neutral stimulus, S2 (e.g., a light), with the already-conditioned S1. In each case, rats express what is learned about S1 and S2 in autonomic and defensive responses indicative of fear in people (Davis, 1992; Fanselow, 1998; McNally and Westbrook, 2006). Following Pavlov (1927), the fear elicited by S1 is termed first-order conditioned fear, and that elicited by S2 is termed second-order conditioned fear (Rizley and Rescorla, 1972; Yin et al., 1994; Parkes and Westbrook, 2010; Witnauer and Miller, 2011; Holmes et al., 2013, 2014; Lay et al., 2018; Leidl et al., 2018).

The formation of first- and second-order conditioned fears requires neuronal activity and NMDA receptor activation in the basolateral amygdala complex (BLA) (Gewirtz and Davis, 1997; Parkes and Westbrook, 2010; Holmes et al., 2013). However, the molecular processes that consolidate these fears within the BLA 
differ in key respects. Consolidation of both types of fear requires CaMKII signaling, gene expression, and DNA methylation (Miller et al., 2002; Monsey et al., 2011). In contrast, consolidation of first-order fear additionally requires ERK/MAPK and PKA/PKC signaling, as well as protein synthesis (Schafe et al., 1999), whereas consolidation of second-order fear occurs independently of these forms of kinase signaling, and does not require protein synthesis in the BLA (Lay et al., 2018).

The differential protein synthesis requirement for consolidating first- and second-order fears is not due to the presence of shock in first-order conditioning and its absence in second-order conditioning (Leidl et al., 2018). This was confirmed using a conditioning protocol in which rats were exposed to S1-shock pairings in Stage 1, and then to the sequence S2-S1-shock (serialorder conditioning) in Stage 2: that is, S2 was paired with S1 as in second-order conditioning, but S1 continued to be paired with shock as in first-order conditioning. Like the fear that accrues to S2 in a standard second-order conditioning protocol, consolidation of fear to S2 in this modified protocol was unaffected by a BLA infusion of the protein synthesis inhibitor cycloheximide immediately following the S2-S1-shock conditioning session. In contrast, the same infusion disrupted consolidation of fear to S2 when S1-shock pairings had been omitted in Stage 1 (i.e., rats just received a session of S2-S1-shock conditioning), showing that, in the group of interest, some aspect of the prior S1 training had rendered consolidation of S2 fear independent of protein synthesis in the BLA.

The present series of experiments used the serial-order conditioning protocol described above to identify how the prior training of S1 affects the protein synthesis requirement for consolidation of fear to S2. In each experiment, rats received a conditioning session in which they were exposed to S2-S1-shock sequences. This session was followed immediately by a BLA infusion of the protein synthesis inhibitor cycloheximide (apart from Experiment $2 \mathrm{~b}$ where the DNA methyltransferase [DNMT] inhibitor, 5-AZA was infused into the BLA). Rats were subsequently tested for the levels of freezing elicited by S2 (and S1). The experiments differed in the pretraining of S1: it was not pretrained in Experiment 1; pretrained as a signal for shock in Experiments $2 \mathrm{a}, 2 \mathrm{~b}$, and 3; pretrained in an explicitly unpaired relation to shock in Experiment 4; and pretrained as a signal for sucrose in Experiment 5. The question of interest was whether consolidation of S2 would be immune to the BLA cycloheximide infusion when any pretrained S1 was present across the S2-S1shock sequences, or whether this immunity would only be evident when S1 had been previously paired with shock.

\section{Materials and Methods}

\section{Subjects}

Subjects were 166 experimentally naive, male adult Sprague Dawley rats, obtained from a commercial supplier (Animal Resources Centre). Rats were housed in plastic tubs ( $22 \mathrm{~cm}$ high $\times 67 \mathrm{~cm}$ long $\times 40 \mathrm{~cm}$ wide), with 8 rats per tub. The tubs were located in a colony room maintained at $20^{\circ} \mathrm{C}-22^{\circ}$, with lights on between 7 A.M. and 7 P.M. Rats were handled each day for at least $5 \mathrm{~d}$ before behavioral procedures began. Food and water were continuously available in the tubs, unless specified otherwise.

\section{Apparatus}

All procedures were conducted in four identical chambers $(30 \mathrm{~cm}$ wide $X$ $26 \mathrm{~cm}$ high $\times 30 \mathrm{~cm}$ deep), each located in sound-attenuating wooden cabinets. The rear and front walls of the chambers were made of Plexiglas, and the side walls and ceiling were made of aluminum. The floor was made of stainless-steel rods ( $7 \mathrm{~mm}$ in diameter, spaced $1.8 \mathrm{~mm}$ apart), through which shock could be delivered via a custom-built generator located in another room in the laboratory. Incandescent light bulbs located on the wall of the cabinet were used to deliver a visual stimulus (flashing at a rate of $3.5 \mathrm{~Hz}, \sim 8$ lux at the center of the chamber), and a speaker located on the back wall of the chamber was used to deliver an auditory stimulus (a square-wave tone; $620 \mathrm{~Hz}, \sim 65 \mathrm{~dB}$, against a background noise of $\sim 45 \mathrm{~dB}$ ). An infrared light inside the chamber allowed each rat to be recorded via a camera mounted on the wall of the cabinet, with every session recorded to a DVD located in another room. MATLAB software (The MathWorks) was used to program stimuli and foot shocks.

\section{Stimuli}

Each experiment used the auditory and visual stimuli, counterbalanced in their roles as S1 and S2, such that the auditory stimulus was S1 and the visual stimulus was $\mathrm{S} 2$ for half of the subjects in each experiment, whereas the visual stimulus was S1 and the auditory stimulus was S2 for the remainder. The unconditioned stimulus (US) was a $0.8 \mathrm{~mA}, 0.5 \mathrm{~s}$ foot shock.

\section{Experimental design, scoring, and statistical analysis}

Most of the experiments used single-factor designs with two independent groups. The exceptions were Experiments 2a and 5, both of which used $2 \times 2$ factorial designs. Experiment 2a included the factors of infusion (administered immediately before or after serial-order training) and drug (vehicle or cycloheximide). However, rats that received infusions of vehicle before or after serial-order conditioning did not significantly differ from each other, and thus were combined into a single Group Vehicle, resulting in a single factor design with three groups: Group Vehicle, Group Pre-CHX, and Group Post-CHX. Experiment 5 included the factors of water access (restricted or not restricted following serialorder training) and drug (vehicle or cycloheximide). However, groups that were or were not water restricted following serial-order conditioning did not differ significantly, and thus the two vehicle groups were combined into a single Group Vehicle, and the two drug groups were combined into a single Group CHX, resulting in a single-factor design with two groups. The designs used, and results obtained, in each experiment are summarized in Table 2.

Freezing, defined as the absence of all movement except that required for breathing (Fanselow, 1980), was the measure of conditioned fear. A time sampling procedure was used in which each rat was scored as either freezing or not freezing every $2 \mathrm{~s}$. A percentage freezing score was then calculated based on the proportion of the total observations during which each rat froze. All test data were scored by the experimenter who was blind to the group allocation of a given rat and cross-scored by an experienced observer who was additionally blind to the purposes of the experiment. The Pearson product moment correlation was calculated to assess the reliability between the scores of the two observers. This correlation was $>0.9$ in all of the experiments. Any discrepancies between the scores were resolved in favor of those by the naive observer.

The principal behavioral data for all experiments were acquisition of freezing to S2 and S1 during training, and the freezing elicited by S2 and S1 at test. Data for S1 and S2 were analyzed separately. Training and test data were analyzed using a contrast testing procedure, involving sets of orthogonal contrasts with a between-subject factor of group and a within-subject factor of trial. The criterion for rejection of the null hypothesis $(\alpha)$ was set at 0.05 . For all significant differences, $95 \%$ CIs were calculated, and effect sizes were computed using Cohen's $d$ for contrasts ( 0.8 is considered a large effect size).

\section{Experiment 1}

The surgical, infusion, and histological procedures described below were used in all subsequent experiments, unless indicated otherwise.

Surgery. All rats were surgically implanted with bilateral cannulas targeting the BLA. Rats were injected intraperitoneally with a combination of $1.3 \mathrm{ml} / \mathrm{kg}$ of the anesthetic ketamine, at a concentration of $100 \mathrm{mg} / \mathrm{ml}$ (Ketapex; Apex Laboratories), and $0.3 \mathrm{ml} / \mathrm{kg}$ of the muscle relaxant, xylazine, at a concentration of $20 \mathrm{mg} / \mathrm{ml}$ (Rompun; Bayer). Rats also received a preoperative subcutaneous injection of the nonsteroidal antiinflammatory, Carprofen (Rymadil; Cenvet Australia) (volume $=1 \mathrm{ml}$ / $\mathrm{kg}$; concentration $=5 \mathrm{mg} / \mathrm{ml}$ ). An anesthetized rat was then placed into a stereotaxic apparatus and two 26 -gauge guide cannulas implanted into 
the brain through two holes drilled in the skull. The tips of the guide cannulas were aimed at the BLA in each hemisphere $(2.4 \mathrm{~mm}$ posterior to bregma, $4.9 \mathrm{~mm}$ lateral to the midline, and $8.2 \mathrm{~mm}$ ventral to bregma). The guide cannulas were secured in position with dental cement and four jeweler's screws. A dummy cannula was kept in each guide at all times, except during infusions. Immediately after surgery, rats were injected intraperitoneally with a prophylactic dose $(0.4 \mathrm{ml})$ of the antibiotic Benacilin and placed on a heating mat until they had recovered from the effects of the anesthetic. They were then returned to their home tubs. Rats were given a minimum of $7 \mathrm{~d}$ to recover from surgery, during which time they were handled and weighed daily. Figure 1 shows the most ventral point of cannulas within the BLA of all subjects that were included in the present study.

Drug infusion. Cycloheximide is the most common drug used to block protein synthesis (Schneider-Poetsch et al., 2010). Its infusion into the BLA after a first-order conditioning session disrupts consolidation of the fear produced by pairings of a neutral stimulus: the conditioned stimulus (CS) and the aversive shock (the US) (e.g., Duvarci et al., 2005). Cycloheximide (Sigma-Aldrich) was dissolved in 70\% ethanol to yield a stock solution with $200 \mu \mathrm{g} / \mu \mathrm{l}$ concentration. This was then diluted 1:4 with ACSF (Sigma Aldrich) to a final concentration of $40 \mu \mathrm{g} / \mu \mathrm{l}$ (Duvarci et al., 2005). Vehicle was made by diluting $70 \%$ ethanol 1:4 with ACSF. Rats received bilateral intra-BLA infusions of cycloheximide or vehicle $(0.5 \mu \mathrm{l}$ per hemisphere). The infusion procedure began by removing dummy caps from the two guide cannulas and inserting 33-gauge internal cannulas. The two internal cannulas were each connected to separate $25 \mu \mathrm{l}$ Hamilton syringes. Drug or vehicle was infused bilaterally into the BLA through the internal cannulas at a rate of $0.25 \mu \mathrm{l} / \mathrm{min}$ by an infusion pump (Harvard Apparatus). Following infusion, the internal cannulas were left in place for an additional $2 \mathrm{~min}$ to allow for diffusion of the drug away from the tips of the cannulas

Histology. Following behavioral testing, rats were killed with an intraperitoneal injection of a lethal dose of sodium pentobarbital, decapitated, their brains rapidly removed and frozen. Brains were sliced on a cryostat into coronal sections of $40 \mu \mathrm{m}$ thickness. Every second section through the BLA was mounted on a glass microscope slide and then stained with cresyl violet. Slides were observed under a microscope to confirm the location of cannulas using the brain atlas of Paxinos and Watson (1997). Rats with inaccurate cannula placements (one or both cannulas positioned outside the boundaries of the BLA) or with extensive damage to the BLA were excluded from the statistical analysis.

Behavioral procedures. Figure 2 shows a schematic diagram of the behavioral procedures used in Experiment 1.

Context preexposure. There were two daily sessions of context preexposure, each lasting $20 \mathrm{~min}$, with one in the morning and the other in the afternoon. This was done to familiarize the rats with the chambers, minimizing any neophobic reactions.

Serial-order conditioning. Rats received four presentations of the sequence S2-S1-shock (serial-order conditioning) on day 3. The durations of S2 and S1 were those used in previous studies of second-order (Lay et al., 2018) and serial-order (Leidl et al., 2018) conditioning. Offset of the $30 \mathrm{~s} \mathrm{~S} 2$ co-occurred with onset of the $10 \mathrm{~s} \mathrm{S1}$, which coterminated in foot shock. The first S2-S1-shock sequence occurred $5 \mathrm{~min}$ after placement in the context, and the duration of the interval between the sequences (intertrial interval [ITI]) was $5 \mathrm{~min}$. All rats remained in the context for 1 min following the final S2-S1 shock sequence. They were then removed and administered an intra-BLA infusion of cycloheximide or vehicle.

Context extinction. Rats were exposed for $40 \mathrm{~min}$ to the context in the absence of any scheduled events on day 4 , and again for $10 \mathrm{~min}$ on the morning of day 5 . This was done to extinguish any freezing elicited by the context and thereby to more clearly reveal freezing elicited by S2 and S1.

Test. Rats were tested for freezing to $S 2$ and $S 1$ on days 5 and 6 , with the order of testing counterbalanced. Rats were placed into the conditioning context and, after a 2 min adaptation period, exposed to S2 or S1. Each test session consisted of eight S2 or S1 presentations (ITI $=3 \mathrm{~min}$ ). Across the test sessions, the durations of S2 and S1 remained 30 and $10 \mathrm{~s}$, respectively. On day 7 , rats underwent an additional test in which $\mathrm{S} 2$ and S1 were presented as a serial compound (i.e., S2-S1) in the absence of the shock US. This was done to assess whether matching the conditions of

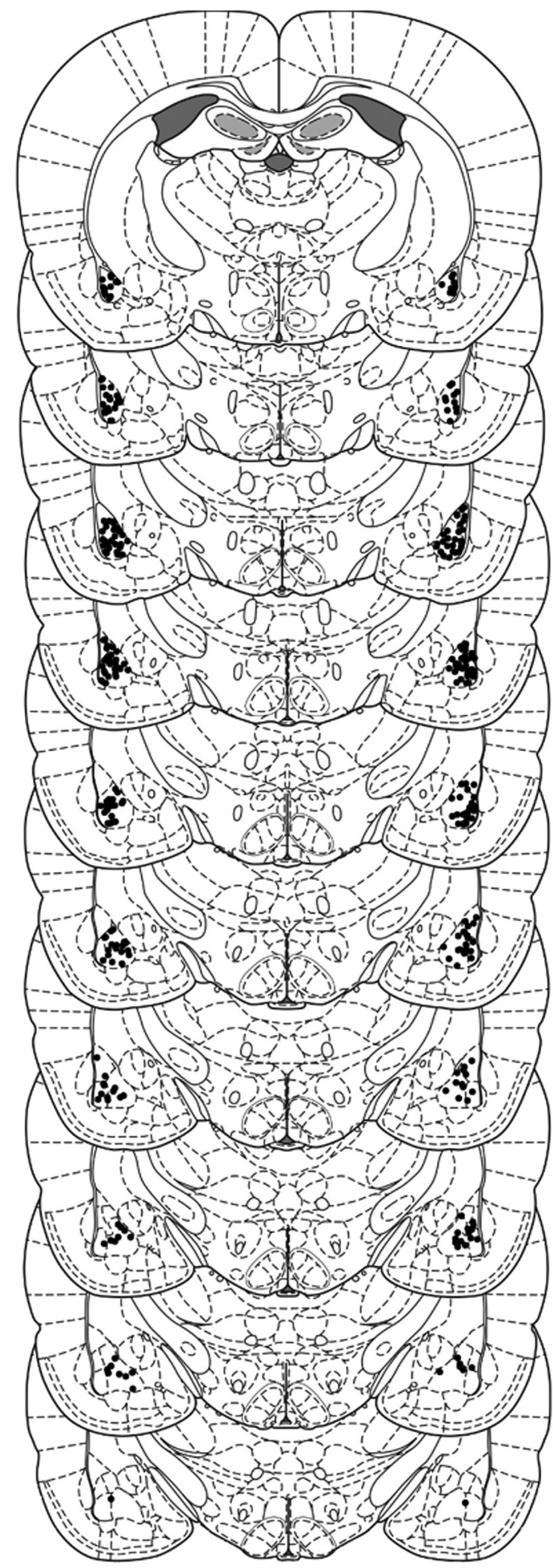

$-1.80$

Figure 1. Cannula placements as verified on Niss-stained sections. Black dots represent the most ventral point of the cannula track for each rat on coronal sections based on the atlas of Paxinos and Watson (2007).

testing to those of training rescued test levels of freezing to S2 and S1 among rats that had previously demonstrated memory deficits on days 5 and 6 . As with the previous tests, rats were placed into the conditioning context and, after a 2 min adaptation period, exposed to eight S2-S1 sequences (ITI $=3 \mathrm{~min})$.

\section{Experiment $2 a$}

Behavioral procedures. Training and test protocols only differed from Experiment 1 in that all rats additionally underwent first-order condi- 
b

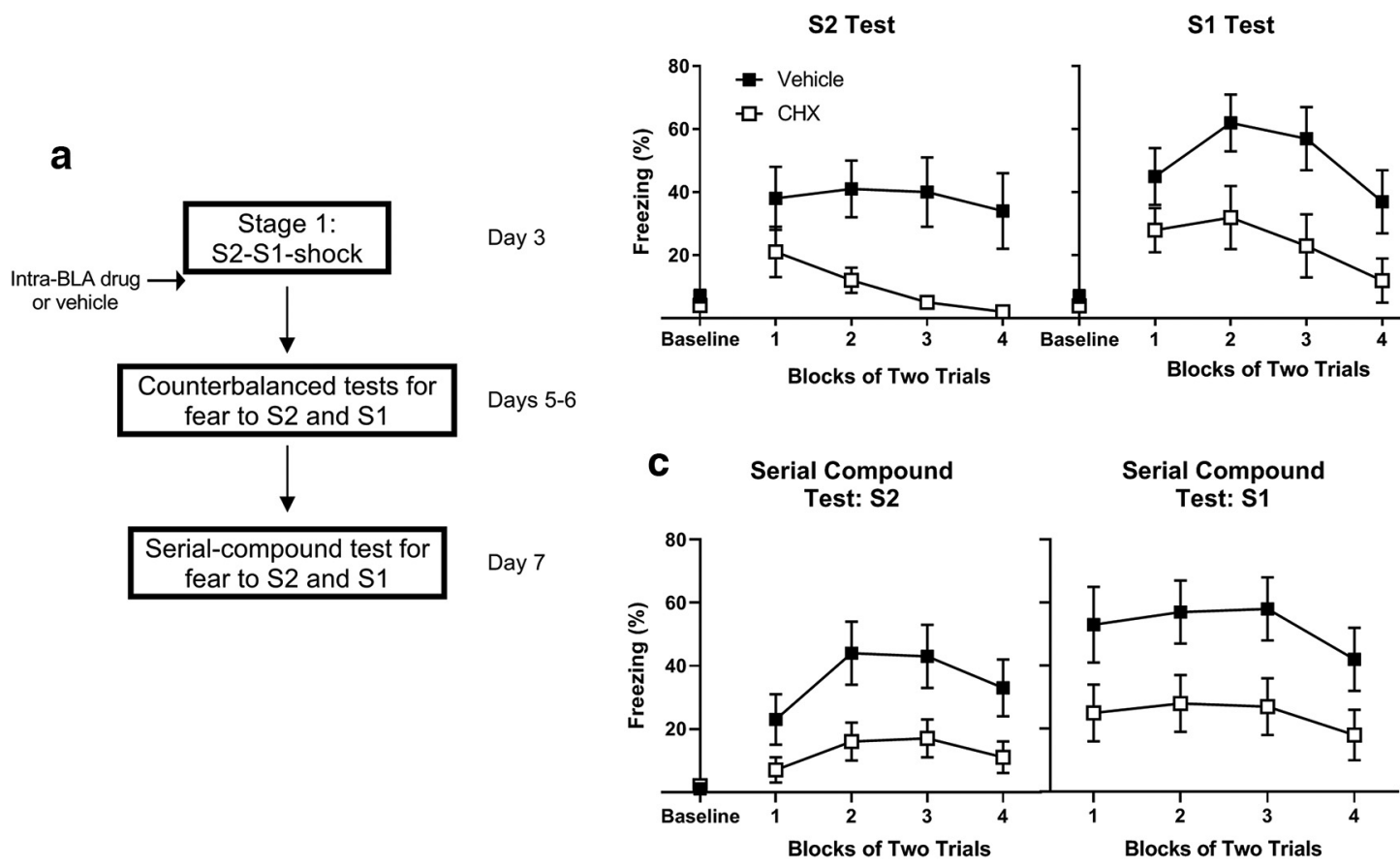

Figure 2. In the absence of prior training, consolidation of fear to $\mathrm{S} 2$ and $\mathrm{S} 1$ requires de novo protein synthesis in the BLA. $\boldsymbol{a}$, Experimental timeline of serial-order conditioning and tests for fear to $S 2$ and $S 1$ for rats treated with vehicle $(n=10)$ and cycloheximide $(n=13)$. Percentage freezing to $S 2$ and $S 1$ during $(\boldsymbol{b})$ counterbalanced tests for fear to each cue individually on days 5 and 6 and (c) serial-compound test presentations on day 7. Open squares represent drug-treated rats. Filled squares represent vehicle-treated rats. Data are mean \pm SEM.

tioning of $\mathrm{S} 1$ on day 3 , followed by two sessions of context extinction on day 4. Figure 3 shows a schematic diagram of the behavioral procedures used in Experiment 2a.

First-order conditioning. Rats received four pairings of S1-shock on day 3. Offset of the $10 \mathrm{~s} \mathrm{S1}$ coterminated in foot shock. The first S1-shock pairing occurred 5 min after placement in the context, the ITI between pairings was $5 \mathrm{~min}$, and rats remained in the context for $1 \mathrm{~min}$ following the final pairing.

Context extinction. The sessions of context extinction on day 4 and the morning of day 5 were performed in the manner described previously. This was done to eliminate any context-elicited freezing, thus permitting a clearer assessment of freezing to S2 and S1 across the serial-order conditioning on the afternoon of day 5 .

Serial-order conditioning and testing protocols were identical to those described. Briefly, rats underwent serial-order conditioning on day 5 , context extinction on day 6 and the morning of day 7 , followed by counterbalanced tests for freezing to $S 2$ and $S 1$ on the afternoons of days 7 and 8 . On day 5 , rats received intra-BLA infusions of cycloheximide or vehicle. Those in Group Pre-CHX received infusions of cycloheximide immediately before, whereas rats in Group Post-CHX received infusions of cycloheximide immediately after the serial order conditioning session. Half of the rats in Group Vehicle received infusions of vehicle before and the remainder after the serial-order conditioning session. As these vehicle-treated rats displayed equivalent levels of freezing during serialorder conditioning and across the subsequent tests for freezing to S2 and S1, they were combined into one composite Group Vehicle control.

Extinction of S2 and its reconditioning and testing as a first-order CS. Test data indicated that infusions of cycloheximide into the BLA after the serial-order conditioning session failed to disrupt consolidation of S2 and S1. Therefore, additional training and testing were conducted to confirm the efficacy of the BLA infusion of cycloheximide. This consisted of extinction of freezing to S2 on days 8 and 9. Two sessions of S2 extinction were conducted to ensure that this stimulus had ceased to elicit freezing before its retraining in the next stage of the experiment. Each extinction session consisted of eight S2 alone presentations. The first presentation occurred $2 \mathrm{~min}$ after placement in the context, and the duration of the ITI was 3 min. Freezing to S2 was extinguished so that it could be retrained as a first-order CS via its pairings with shock. Rats received four S2-shock pairings on day 11. The first S2-shock pairing occurred $5 \mathrm{~min}$ after placement in the context, and the ITI was $5 \mathrm{~min}$. Each 30 s presentation of S2 coterminated in the onset of foot shock. Rats received intra-BLA infusions either immediately before or after S2-shock training. Rats were reassigned to groups such that rats administered the drug before the serial-order session now received the drug after the firstorder session, and rats administered the drug after the serial session now received it before the first-order session. Control rats given vehicle before the serial session were also given vehicle before or after the first-order session. Rats received a 20 min context extinction on day 12 , and a further 10 min context extinction session on the morning of day 13. On the afternoon of day 13, rats were tested with S2 in the manner described previously: the first of the eight $30 \mathrm{~s} \mathrm{S2}$ presentations occurred 2 min after placement in the chamber, and the ITI was $3 \mathrm{~min}$.

\section{Experiment $2 b$}

Behavioral procedures. Training and testing protocols were identical to those in Experiment 2a. This experiment differed only in the drugs with which rats were infused following serial-order conditioning. Rats were infused with either 5-AZA (a demethylation reagent that triggers the breakdown of methyltransferase enzymes on DNA) dissolved in DMSO at $2 \mu \mathrm{g} / \mu \mathrm{l}$, which was then mixed with ACSF at a ratio of 1:1, or vehicle consisting of DMSO and ACSF at a ratio of 1:1 (Maddox et al., 2014; Lay et al., 2018). Figure 4 shows a schematic diagram of the behavioral procedures used in Experiment $2 \mathrm{~b}$.

\section{Experiment 3}

Behavioral procedures. Training and testing protocols were identical to those in Experiment 2a, except that, after first-order conditioning of S1 on day 3 , all rats underwent extinction of S1. Figure 5 shows a schematic diagram of the behavioral procedures used in Experiment 3.

Extinction of S1 before serial-order conditioning. Rats received six sessions of S1 extinction across days 4-6, with two extinction sessions per day (morning and afternoon). Each extinction session consisted of 16 


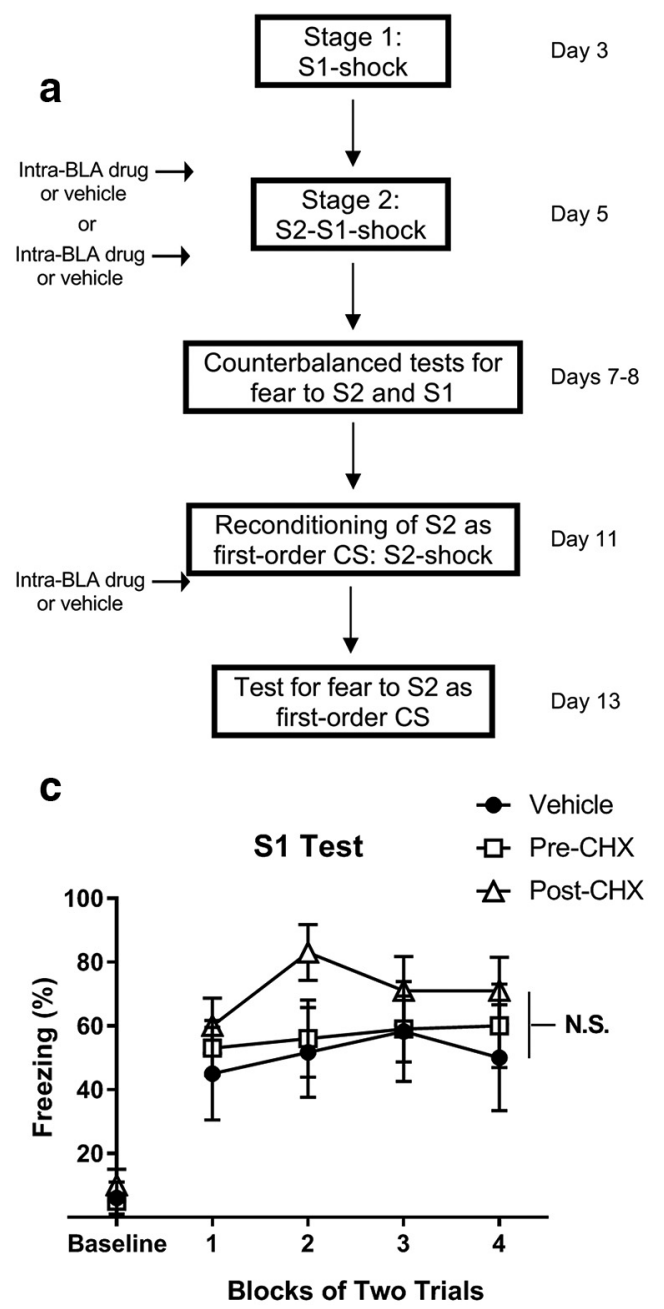

b

S2 Test

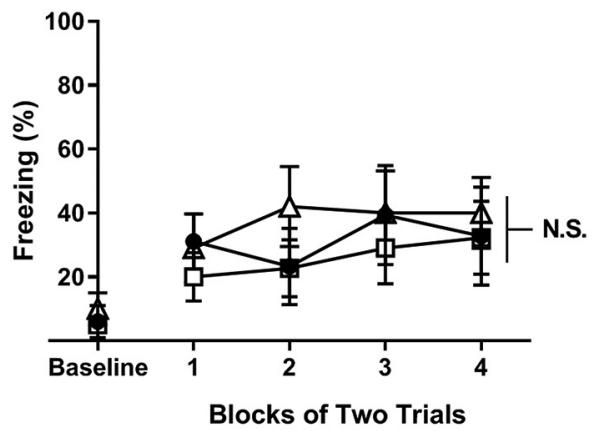

d

S2 Test as First-Order CS

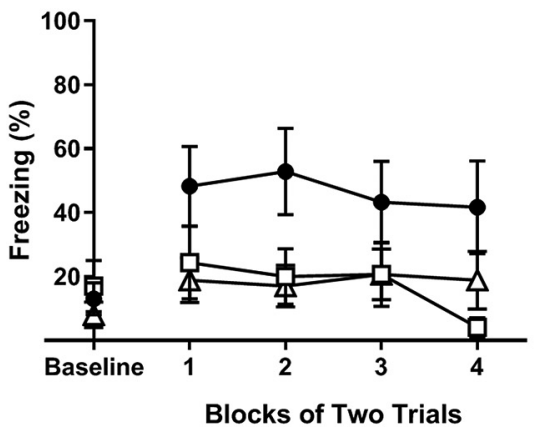

Figure 3. When rats have already undergone S1-shock training, consolidation of fear to S2 and S1 was unaffected by BLA infusions of cycloheximide administered before or after serial-order conditioning. $\boldsymbol{a}$, Experimental timeline of fear conditioning and tests for fear to $S 2$ and $S 1$ for rats treated with vehicle $(n=6)$ and with cycloheximide before $(n=10)$ or after $(n=10)$ serial-order conditioning. Percentage freezing during counterbalanced tests for fear to $(\boldsymbol{b}) S 2$ and $(\boldsymbol{c}) S 1$ on days 5 and 6 and $(\boldsymbol{d})$ to presentations of $S 2$ on day 13 following its extinction and reconditioning as a first-order CS. Closed circles represent rats treated with vehicle. Open squares represent rats treated with cycloheximide immediately before serial-order conditioning. Open triangles represent rats treated with cycloheximide after serial-order conditioning. Data are mean \pm SEM. N.S., nonsignificant.

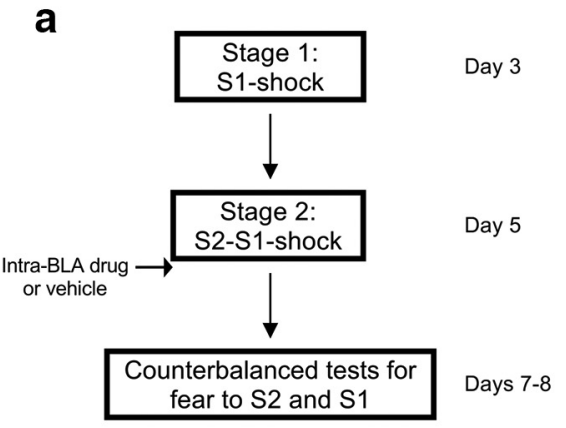

b

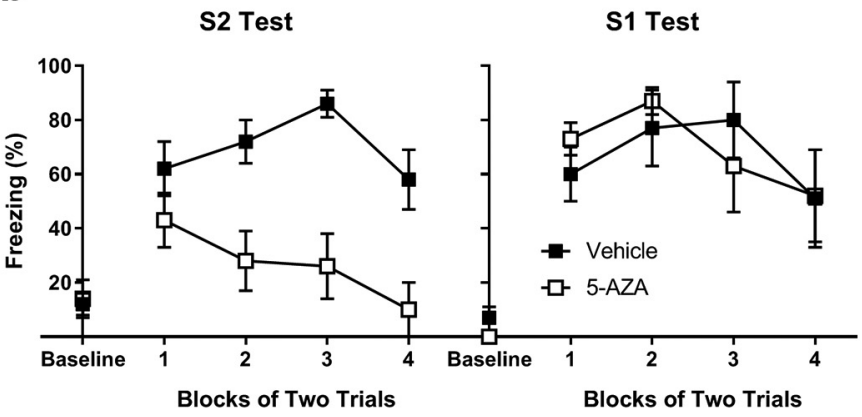

Figure 4. When rats have already undergone S1-shock training, BLA infusions of 5-AZA administered immediately after serial-order conditioning disrupt consolidation of fear to 52 but have no effect on fear to the already-conditioned S1. $\boldsymbol{a}$, Experimental timeline of fear conditioning and tests for fear to S2 and S1 for rats infused with vehicle $(n=15)$ or 5 -AZA ( $n=14)$ immediately after serial-order conditioning. $\boldsymbol{b}$, Percentage freezing during counterbalanced tests for fear to $\mathrm{S} 2$ and $\mathrm{S} 1$ on days 7 and 8 . Closed squares represent rats treated with vehicle. Open squares represent rats treated with 5-AZA. Data are mean \pm SEM.

nonreinforced presentations of S1 (ITI $=2 \mathrm{~min}$ ), with the first S1 presentation occurring $2 \mathrm{~min}$ after placement in the context. All rats remained in the context for $1 \mathrm{~min}$ following the final presentation of S1.

Subsequent behavioral protocols were as previously described. Briefly, rats underwent serial-order conditioning on day 7 followed immediately by infusions of cycloheximide or vehicle. There were two sessions of context extinction on day 8 , one in the morning and the other in the afternoon, a further brief context extinction on the morning of day 9, and counterbalanced tests for freezing to S2 and S1 on days 9 and 10 . 


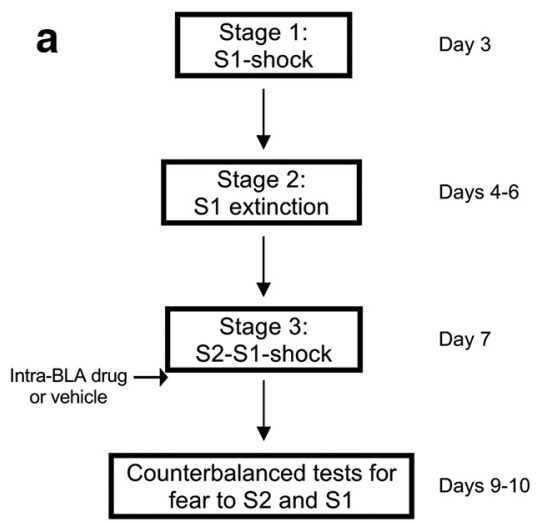

b

S2 Test

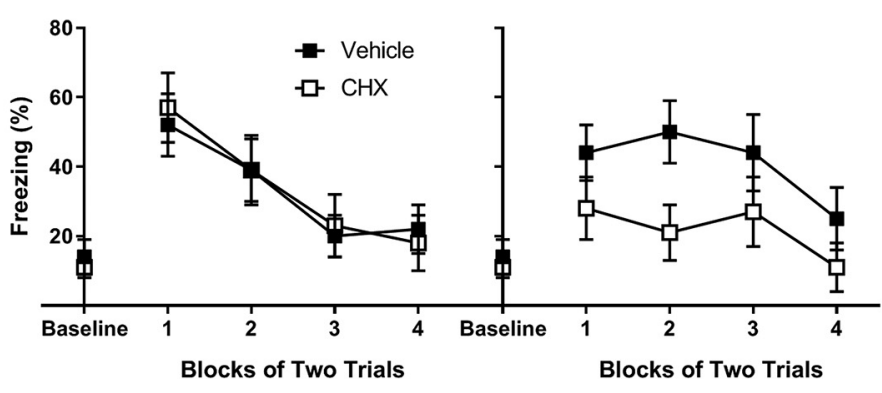

Figure 5. When rats undergo S1-shock training and S1 extinction before S2-S1-shock training, BLA infusions of cycloheximide administered immediately after serial-order conditioning do not affect consolidation of fear to $S 2$ but impair consolidation of the reconditioned fear to $S 1$. $a$, Experimental timeline of fear conditioning and tests for fear to $S 2$ and $S 1$ for rats infused with vehicle $(n=$ 14) or cycloheximide $(n=11)$ after serial-order conditioning. $\boldsymbol{b}$, Percentage freezing during counterbalanced tests for fear to $S 2$ and $S 1$ on days 9 and 10. Closed squares represent rats treated with vehicle. Open squares represent rats treated with cycloheximide. Data are mean \pm SEM.

a

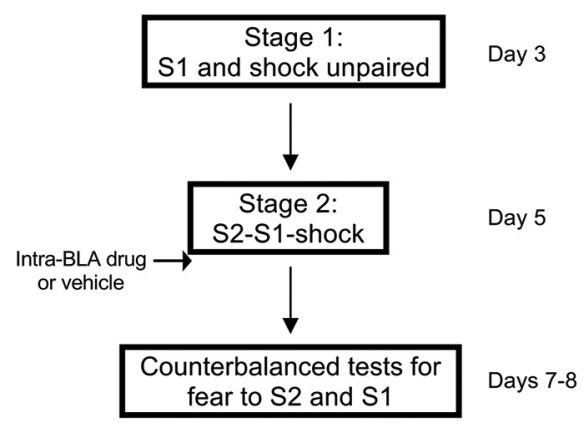

b

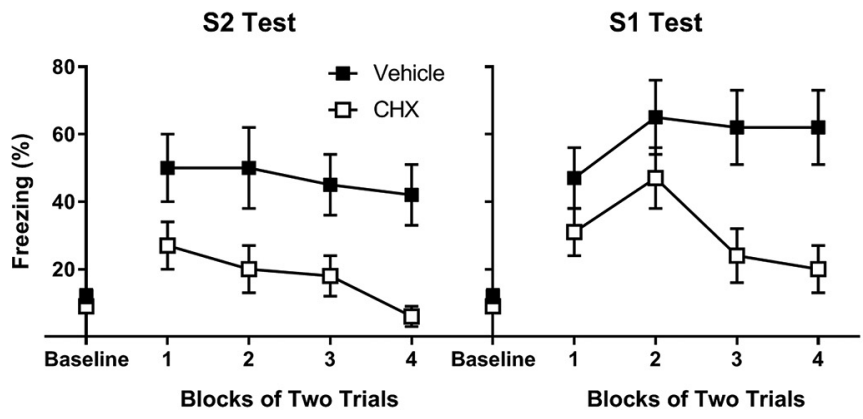

Figure 6. When pretraining consists of unpaired presentations of $S 1$ and the shock US, consolidation of fear to $S 2$ and $S 1$ requires de novo protein synthesis in the BLA. $\boldsymbol{a}$, Experimental timeline of the stages of training and tests for fear to S2 and S1 for rats treated with vehicle $(n=13)$ and cycloheximide $(n=16) . \boldsymbol{b}$, Percentage freezing during counterbalanced tests for fear to $S 2$ and S1 on days 7 and 8 . Closed squares represent rats treated with vehicle. Open squares represent rats treated with cycloheximide. Data are mean \pm SEM.

\section{Experiment 4}

Behavioral procedures. Training and testing protocols were identical to those of Experiment 2a, except that on day 3 all rats received explicitly unpaired presentations of S1 and shock. Figure 6 shows a schematic diagram of the behavioral procedures used in Experiment 4.

Unpaired presentations of $S 1$ and foot shock. Rats received four explicitly unpaired presentations of $S 1$ and the foot shock on day 3 such that S1 was presented four times at the beginning of the session, spaced $2 \mathrm{~min}$ apart, with the first presentation occurring $5 \mathrm{~min}$ into the session. The first foot shock occurred $5 \mathrm{~min}$ after the offset of the final S1 presentation, followed by the remaining three foot shocks spaced 2 min apart. All rats remained in the context for $1 \mathrm{~min}$ following the fourth shock.

Subsequent behavioral protocols were the same as those described in Experiment 2a. Briefly, rats underwent two sessions of context extinction on day 4 , serial-order conditioning on day 5 , a context extinction session on the morning and afternoon of day 6 , a further brief context extinction session on the morning on day 7 , and counterbalanced tests for freezing to $S 2$ and $S 1$ on days 7 and 8 . Immediately after the serial-order conditioning on day 5 , rats received intra-BLA infusions of cycloheximide or vehicle.

\section{Experiment 5}

Behavioral procedures. Figure 7 shows a schematic diagram of the behavioral procedures used in Experiment 5.

S1-sucrose training. All rats received appetitive conditioning across days $1-8$. Each of the daily sessions consisted of four S1-sucrose pairings with an ITI of $5 \mathrm{~min}$. Each presentation of the $10 \mathrm{~s} \mathrm{S1}$ coterminated in delivery of a $20 \%$ sucrose solution into the magazine via a rubber tube connected to an osmotic pump located on top of the chamber. All rats were restricted to $2 \mathrm{~h}$ of water access per day during this stage of training to facilitate appetitive conditioning. Water access was provided $\sim 1 \mathrm{~h}$ after each conditioning session. Following the final session on day 8 , half of the rats remained water restricted for the duration of the experiment in order that the subsequent serial-order conditioning and testing were conducted under the fluid restriction schedule that had been present during the appetitive conditioning. The other half of the rats received continuous access to water in their home cages in order that the subsequent serial-order conditioning and testing were conducted under the conditions (continuous access to water) present in the other experiments.

Serial-order conditioning. On day 9, rats received serial-order fear conditioning in the manner described previously. This was followed by a BLA infusion of cycloheximide or vehicle. There were thus four groups (fluid restricted or not across serial order conditioning and testing $\times$ infusion of cycloheximide or vehicle). However, there were no significant differences between the two vehicle groups or the two drug groups. Therefore, the two vehicle groups were combined to form a composite Group Vehicle, and the two drug groups were combined to form a composite Group CHX. Subsequent behavioral protocols were the same as the previous experiments. Briefly, rats underwent a context extinction on the morning and afternoon of day 6 , a further brief context extinction session on the morning on day 7 , and counterbalanced tests for freezing to $\mathrm{S} 2$ and $\mathrm{S} 1$ on days 7 and 8 .

\section{Results}

Experiment 1

This experiment examined whether, in the absence of any prior training, consolidation of the fears produced by exposing rats to 
a

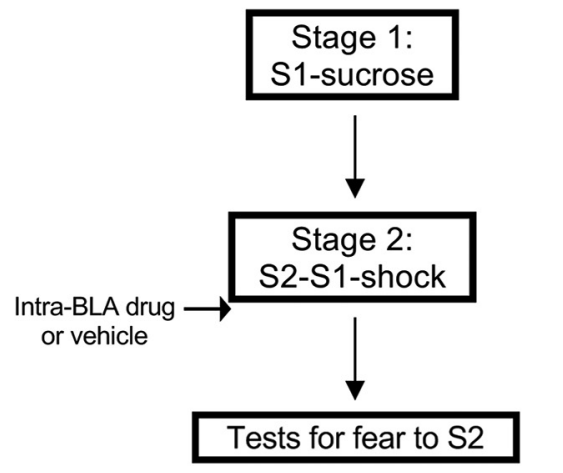

b

Days 1-8

Day 9

Days $11-12$
S2 Test

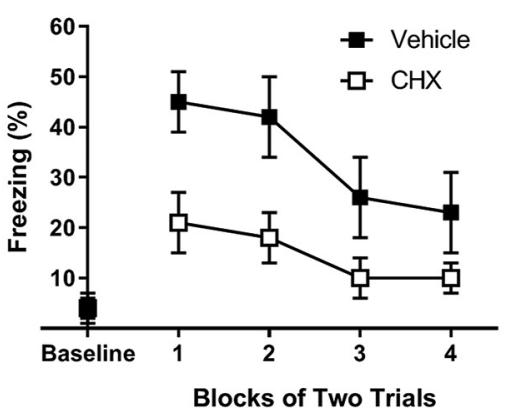

Figure 7. When pretraining consists of appetitive S1-sucrose pairings, consolidation of fear to S2 requires de novo protein synthesis in the BLA. $\boldsymbol{a}$, Experimental timeline of the stages of training and tests for fear to $\mathrm{S} 2$ for rats treated with vehicle $(n=17)$ and cycloheximide $(n=17)$. $\boldsymbol{b}$, Percentage freezing during tests for fear to $S 2$ on days 11 and 12 . Closed squares represent rats treated with vehicle. Open squares represent rats treated with cycloheximide. Data are mean \pm SEM.

Table 1. Mean ( \pm SEM) levels of performance to S1 and S2 during their first two (left columns) and final two (right columns) presentations in each stage of training across all experiments ${ }^{a}$

\begin{tabular}{|c|c|c|c|c|c|c|c|c|}
\hline \multirow{4}{*}{$\begin{array}{l}\text { Experiment } \\
1\end{array}$} & \multirow{4}{*}{$\begin{array}{l}\text { Groups } \\
\\
\text { Vehicle } \\
\text { CHX }\end{array}$} & \multicolumn{3}{|c|}{ Stage 1} & \multicolumn{4}{|c|}{ Stage 2} \\
\hline & & & & & \multicolumn{2}{|c|}{$\$ 2$} & \multicolumn{2}{|c|}{ S1 } \\
\hline & & \multirow{2}{*}{\multicolumn{2}{|c|}{-}} & & $21(5)$ & $88(4)$ & $29(5)$ & $83(7)$ \\
\hline & & & & & $20(7)$ & $69(8)$ & $21(8)$ & $69(9)$ \\
\hline & & \multicolumn{2}{|c|}{ S1 } & & \multicolumn{2}{|c|}{ S2 } & \multicolumn{2}{|c|}{ S1 } \\
\hline \multirow[t]{4}{*}{$2 a$} & Vehicle & $14(7)$ & $60(12)$ & & $29(6)$ & $73(9)$ & $52(13)$ & $63(16)$ \\
\hline & Pre-CHX & $9(3)$ & 64 (11) & & $43(6)$ & $75(9)$ & $51(11)$ & 50 (14) \\
\hline & Post-CHX & $21(7)$ & $73(13)$ & & $33(12)$ & $53(13)$ & $49(12)$ & $44(16)$ \\
\hline & & & & & & & & \\
\hline \multirow[t]{4}{*}{$2 b$} & Vehicle & $24(5)$ & $83(6)$ & & $57(8)$ & $82(7)$ & $64(9)$ & $62(10)$ \\
\hline & 5-AZA & $20(5)$ & $71(9)$ & & $48(5)$ & $76(7)$ & $55(9)$ & $58(10)$ \\
\hline & & \multicolumn{2}{|c|}{ Stage 1} & Stage 2 & \multicolumn{4}{|c|}{ Stage 3} \\
\hline & & \multicolumn{2}{|c|}{ S1 } & S1 & \multicolumn{2}{|c|}{ S2 } & \multicolumn{2}{|c|}{ S1 } \\
\hline \multirow[t]{4}{*}{3} & Vehicle & $18(4)$ & $71(8)$ & $12(3)$ & $38(7)$ & $76(6)$ & $55(7)$ & $73(8)$ \\
\hline & CHX & $23(6)$ & $72(10)$ & $10(3)$ & $45(6)$ & $78(8)$ & $49(10)$ & 69 (12) \\
\hline & \multicolumn{4}{|c|}{ Stage 1} & \multicolumn{4}{|c|}{ Stage 2} \\
\hline & & \multicolumn{2}{|c|}{ S1 } & & \multicolumn{2}{|c|}{ S2 } & \multicolumn{2}{|c|}{ S1 } \\
\hline \multirow[t]{3}{*}{4} & Vehicle & $7(5)$ & $12(6)$ & & $41(10)$ & $65(10)$ & $42(8)$ & $73(8)$ \\
\hline & CHX & $3(2)$ & $8(6)$ & & $26(7)$ & $55(9)$ & $32(8)$ & $67(9)$ \\
\hline & & \multicolumn{2}{|c|}{ S1 } & & \multicolumn{2}{|c|}{$\$ 2$} & \multicolumn{2}{|c|}{ S1 } \\
\hline \multirow[t]{2}{*}{5} & Vehicle & $9(2)$ & $19(3)$ & & $18(5)$ & $59(7)$ & $11(4)$ & $59(9)$ \\
\hline & CHX & $9(2)$ & $18(2)$ & & $13(4)$ & $68(8)$ & $9(4)$ & $56(9)$ \\
\hline
\end{tabular}

${ }^{a}$ The only exception is Stage 2 of Experiment 3 , where the data reflect average performance to $S 1$ throughout its eight presentations during the final extinction session on day 6 . All values correspond to mean levels of freezing, except for Stage 1 of Experiment 5 , in which the measure of learning and memory for the S1-sucrose association was rats' rate of magazine entries per minute.

serial-order, S2-S1-shock conditioning requires de novo protein synthesis in the BLA. Immediately after serial-order conditioning, one group received a BLA infusion of cycloheximide (Group $\mathrm{CHX}$ ) whereas the other received a BLA infusion of vehicle only (Group Vehicle). Both groups were then tested for fear (freezing) to S2 and S1, and subsequently to serial presentations of the S2-S1 compound (for a schematic, see Fig. 2a).

Table 1 shows mean levels of performance to S1 and S2 averaged across their two final presentations in each stage of training in this and all subsequent experiments. The levels of freezing to S2 and $\mathrm{S} 1$ increased linearly across the conditioning trials (main effect of trials for freezing to S2, $F_{(1,21)}=86.5, p<0.001$; and S1, $\left.F_{(1,21)}=58.1, p<0.001\right)$, and there were no significant between- group differences in freezing to $\mathrm{S} 2$ or $\mathrm{S} 1$ ( $F$ values $<2.1, F c=4.3$, $p>0.16)$ or trial $\times$ group interactions $(F$ values $<2.4, p>0.13)$.

Figure $2 b$ shows the test levels of freezing to S2 (left) and S1 (right) averaged across blocks of two trials. The statistical analyses confirmed what is clear from inspection of the figure: rats in Group CHX froze significantly less than those in Group Vehicle to both $\mathrm{S} 2\left(F_{(1,21)}=12.8, p<0.01, d=1.4,95 \% \mathrm{CI}=11.8,44.7\right)$ and $\mathrm{S} 1\left(F_{(1,21)}=8.3, p<0.01, d=1.2,95 \% \mathrm{CI}=7.4,45.8\right)$. The main effects of trials and trial $\times$ group interactions were not significant $(F$ values $<3.8, F c=4.3, p>0.06)$.

$\mathrm{S} 2$ and $\mathrm{S} 1$ were presented in a serial compound during training but individually at test. To assess the possibility that the rats in Group CHX might demonstrate intact memory when the condi- 
tions of testing were more closely matched to those of conditioning, all rats received an additional test session on day 7 in which they were exposed to serial S2-S1 presentations in the absence of the shock US. Figure $2 c$ shows levels of freezing to S2 (left) and S1 (right) during this test session. The statistical analysis confirmed what is evident from inspection of the figure: rats in Group CHX froze at significantly lower levels than Group Vehicle to both S2 $\left(F_{(1,21)}=17.9, p<0.01, d=1.8,95 \% \mathrm{CI}=11.9,34.8\right)$ and $\mathrm{S} 1$ $\left(F_{(1,21)}=9.9, p<0.01, d=1.3,95 \% \mathrm{CI}=7.4,45.8\right)$. The main effects of trials and trial $\times$ group interactions were not significant ( $F$ values $<1.3, F c=4.3, p>0.26)$, indicating that the two groups froze at consistently different levels across the serialcompound presentations, and that their levels of freezing did not significantly decline across the test session. Together, these data indicate that post-training infusions of cycloheximide disrupted consolidation of fear to both S2 and S1, and that this disruption was not due to the cues being conditioned in the serial-compound but tested individually.

There were no statistically significant group differences in levels of freezing during baseline (first $2 \mathrm{~min}$ ) at the beginning of any training or test session in this experiment, and in all subsequent experiments (all $p>0.08$ ). Therefore, baseline levels of freezing in the subsequent experiments will be indicated in each of the figures but will not be further discussed.

\section{Experiment 2a}

This experiment sought to replicate and extend the finding reported by Leidl et al. (2018) that the presence of an already-fearconditioned S1 in the S2-S1-shock protocol alters the protein synthesis requirement for consolidation of fear to S2. Four groups of rats were exposed to S1-shock pairings in Stage 1, S2S1-shock sequences (serial-order conditioning) in Stage 2, and were then tested for fear to S2 and S1 in Stage 3. The groups differed with respect to the timing and identity of the BLA infusions that they received in Stage 2: one group received a BLA infusion of cycloheximide before the serial-order session, whereas a second received this infusion after that session. The remaining two groups received a BLA infusion of vehicle either before or after the serial-order session (for a schematic, see Fig. $3 a$ ). Experiment 1 showed that a post-training infusion of cycloheximide into the BLA disrupted consolidation of fear to both S1 and S2. In contrast, we expected that the presence of the fearconditioned S1 would render S2 immune to the disruptive effect of a cycloheximide infusion into the BLA and, likewise, that the already-conditioned S1 would be unaffected by the BLA infusion of cycloheximide.

The rats infused with vehicle either before or after serial-order conditioning exhibited equivalent levels of performance during all training and test sessions (data not shown). Therefore, they were combined into a single composite control group, and the results are described with respect to three groups: those that received BLA infusions of vehicle (Group Vehicle), cycloheximide before Stage 2 (Group Pre-CHX), and cycloheximide after Stage 2 (Group Post-CHX). Importantly, the statistical analysis produced the same results when the data were analyzed as a $2 \times 2$ factorial design (with factors of infusion time [immediately preserial order or post-serial order] and infusion type [vehicle or cycloheximide]), or as the three groups just described. Thus, the decision to combine the control rats into a single Group Vehicle did not affect the results.

Rats in all three groups acquired freezing to $S 1$ at equivalent rates across its pairings with shock in Stage 1 (Table 1). There was a significant main effect of trials $\left(F_{(1,23)}=90.3, p<0.001\right)$, but no main effect of group or trial $\times$ group interaction $(F$ values $<1.6$, $F c=4.3, p>0.21)$. All rats also acquired freezing to S2 at equivalent rates in Stage 2 while maintaining similar levels of freezing to $S 1$. There was a significant main effect of trials $\left(F_{(1,23)}=68.8\right.$, $p<0.001$ ), but no significant main effect of group, or trial $\times$ group interaction (all $F$ values $<3.5, F c=4.3, p>0.07$ ) for freezing to $S 2$, nor any significant main effects of group, trials, or trial $\times$ group interaction $(F$ values $<1.5, p>0.23)$ for freezing to $S 1$.

Figure $3 b, c$ shows test levels of freezing to S2 and S1. In contrast to the results of the previous experiment, it is clear that the BLA infusion of cycloheximide failed to disrupt consolidation of fear to S2 or S1, regardless of whether it was administered before or after the serial-order conditioning session. The statistical analysis confirmed that there were no significant differences in the levels of freezing elicited by S2 in the control and drug groups, nor between the drug groups; and there were no significant trial $\times$ group interactions $(F$ values $<1)$. Likewise, there were no significant differences in freezing to $S 1$ between the control and drug groups, nor between the two drug groups ( $F$ values $<1.7$, $F c=4.3, p>0.20)$; and there were no significant trial $\times$ group interactions $(F<1)$. Finally, there were no significant linear trends across test presentations of S2 or S1 ( $F$ values $<2.7, p>$ 0.11 ), indicating that the levels of freezing did not decline across the presentations.

To exclude the possibility that the failure to detect effects on consolidation was due to the ineffectiveness of the drug, we sought to replicate, within these same animals, the wellestablished effect of BLA cycloheximide infusions on consolidation of first-order conditioned fear. Therefore, S2 was extinguished on days 9 and 10 and then reconditioned as a firstorder CS across four S2-shock pairings on day 11 (for a schematic, see Fig. $3 a$ ). This was followed by context extinction on day 12 , a further brief context extinction session on the morning of day 13, and a test for fear to S2 in the afternoon of day 13. To reduce the possibility that rats' prior training/infusion history could affect their reconditioning, for this portion of the experiment, we reassigned rats to new conditions in such a way that no individual rat was in the same experimental condition as before: that is, rats in any one condition from the first part of this experiment (serial-order conditioning) were distributed equally across the other two conditions in the second part (reconditioning).

Extinction of S2 on days 9 and 10 was successful as was reconditioning of S2 across its pairings with shock on day 11 (Table 1). All three groups reacquired freezing to S2 as a first-order CS at similar rates: there was a significant main effect of trials $\left(F_{(1,23)}=\right.$ $36.3, p<0.001$ ), but no significant differences between the control and drug groups, nor between the two drug groups, and no significant trial $\times$ group interactions $(F$ values $<3.5, F c=4.3$, $p>0.07)$. Figure $3 d$ shows test levels of freezing to S2 as a firstorder CS. The analysis confirmed what is clear from inspection of the figure: rats in Group Vehicle froze significantly more across test presentations of S2 than rats in Groups Pre-CHX and Post$\operatorname{CHX}\left(F_{(1,23)}=10.4, p<0.01, d=1.2,95 \% \mathrm{CI}=10.2,46.7\right)$; and rats in Groups Pre-CHX and Post-CHX froze at similarly low levels $(F$ values $<1)$. Thus, the failure of intra-BLA cycloheximide infusions to disrupt consolidation of fear to S2 or of the already-conditioned S1 in the serial protocol was not due to ineffectiveness of the drug.

\section{Experiment 2b}

Lay et al. (2018) reported that consolidation of the second-order fear produced by pairings of a novel S2 and an already- 
conditioned S1 requires DNA methylation but not protein synthesis in the BLA. The previous experiment showed that protein synthesis in the BLA is also not required for consolidation of the fear that accrues to S2 in the modified second-order conditioning protocol (S1-shock in Stage 1, S2-S1-shock in Stage 2). Therefore, the present experiment examined whether DNA methylation in the BLA is required to consolidate fear of S2 in this protocol. Specifically, it examined whether, relative to a BLA infusion of vehicle, consolidation of S2 (and of the already-conditioned S1) was disrupted when the S2-S1-shock session was immediately followed by a BLA infusion of a drug (5-AZA) that triggers the breakdown of DNMT enzymes on DNA.

Training and testing procedures were the same as those used in Experiment 2a (for a schematic, see Fig. 4a). As in all other experiments, the present experiment tested freezing to S2 and S1 in a counterbalanced fashion. However, in contrast to the other experiments, in this experiment the levels of freezing declined substantially between the first and second test sessions (data not shown). We are unclear why this occurred other than to note that low levels of freezing in the second of the two tests could be due to the vehicle used for administration of 5-AZA. In contrast to the experiments involving cycloheximide, where the vehicle was a 1:4 combination of $70 \%$ ethanol and ACSF, the vehicle in the present experiment was a 1:1 combination of DMSO and ACSF. It is well established that DMSO, in high concentrations, can be toxic (Brayton, 1986). Although we were unable to detect any evidence of toxicity in the histological assessment of the BLA tissue from this experiment, the DMSO and ACSF vehicle, which was administered to both the treatment and control groups, may have exerted some effect in the amygdala that served to produce the rapid decline in freezing from the first to the second test. Given this decline in freezing, the statistical analyses were restricted to data from the first test of S1 and S2, thereby allowing a clearer assessment of the effect of 5-AZA on consolidation of the S1 and S2 memories.

First-order conditioning was successful (Table 1). Rats in both groups acquired freezing to $\mathrm{S} 1$ across its pairings with shock in Stage $1\left(F_{(1,27)}=277.9, p<0.001\right)$, and did so at equivalent rates, as there was no significant effect of group or trial $\times$ group interactions $(F$ values $<1, F c=4.2)$. Serialorder conditioning was also successful. All rats acquired freezing to S2 and maintained freezing to S1 across the S2-S1-shock sequences. The analysis of freezing to $\mathrm{S} 2$ revealed a significant main effect of trials $\left(F_{(1,27)}=61.3, p<0.001\right)$, but no significant main effect of group nor any significant trial $\times$ group interaction ( $F$ values $<1.2, p>0.28$ ). The analysis of freezing to $S 1$ revealed no significant differences between the control and drug groups, no effect of trials, and no trial $\times$ group interaction $(F$ values $<1)$.

The statistical analysis confirmed what is clear from inspection of Figure 4: the BLA infusions of 5-AZA had disrupted consolidation of fear to S2 but not to the already-conditioned S1. There was a significant drug (vehicle vs 5 -AZA) $\times$ test stimulus $(\mathrm{S} 2$ vs $\mathrm{S} 1)$ interaction $\left(F_{(1,25)}=11.8, p<0.01, \eta_{\mathrm{p}}^{2}=0.32,95 \%\right.$ $\mathrm{CI}=8.9,35.4)$, as well as a significant main effect of group for freezing to $\mathrm{S} 2\left(F_{(1,14)}=24.9, p<0.001, d=2.5,95 \% \mathrm{CI}=24.3\right.$, $60.9)$, but not for freezing to $S 1(F<1, F c=4.2)$. There were no main effects of trial, nor trial $\times$ group interactions, for freezing elicited by test presentations of $\mathrm{S} 2$ or $\mathrm{S} 1$ ( $F$ values $<3.5, p>0.07$ ), suggesting that levels of freezing did not significantly decline throughout the test sessions.

\section{Experiment 3}

Experiment 2a showed that consolidation of fear to S2 was unaffected by a BLA infusion of cycloheximide when the S2-S1-shock sequences contained an already-conditioned S1. Experiment 3 examined whether consolidation of this fear is also unaffected when the conditioned S1 had been extinguished before the S2S1-shock sequences. All rats were exposed to S1-shock pairings in Stage 1, repeated presentations of S1 alone in Stage 2, and the S2-S1-shock sequences in Stage 3. Rats received a BLA infusion of vehicle or cycloheximide immediately after the S2-S1-shock session, and were subsequently tested with S2 and S1 in a counterbalanced order (for a schematic, see Fig. $5 a$ ).

Fear conditioning of S1 was successful (Table 1). There was a significant effect of trials $\left(F_{(1,23)}=135.2, p<0.001\right)$, but no main effect of group nor a trial $\times$ group interaction $(F$ values $<1)$. Extinction of that fear across the twice-daily sessions on days 4-6 was also successful. The mean levels of freezing during the first session were as follows: $68 \%(\mathrm{SEM}=5 \%)$ for Group Vehicle, and $65 \%(\mathrm{SEM}=5 \%)$ for Group CHX; mean freezing during the final session were as follows: $12 \%(\mathrm{SEM}=3 \%)$ for Group Vehicle, and 10\% (SEM = 3\%) for Group CHX (Table 1). The statistical analysis confirmed that there was a significant main effect of session $\left(F_{(1,23)}=214.7, p<0.001\right)$, but no main effect of group nor a significant session $\times$ group interaction $(F$ values $<1)$. Rats in both groups developed freezing to S2 and redeveloped freezing to $\mathrm{S} 1$ across the $\mathrm{S} 2-\mathrm{S} 1$-shock session. There were significant main effects of trials for S2 $\left(F_{(1,23)}=107.5, p<0.001\right)$ and $S 1\left(F_{(1,23)}=\right.$ 16.0, $p<0.01)$ but no main effects of group nor trial $\times$ group interactions $(F$ values $<1)$.

Inspection of the test data in Figure $5 b$ suggests that cycloheximide had contrasting effects on consolidation of fear to S2 and S1: both groups froze at equivalent levels across test presentations of S2, while Group CHX froze less than Group Vehicle across test presentations of $S 1$. This was confirmed in the statistical analysis. There was a significant group $\times$ test type interaction $\left[F_{(1,23)}=\right.$ $4.5, p=0.04$, partial $\eta$ squared $\eta_{\mathrm{p}}^{2}=0.16,95 \% \mathrm{CI}=0.5,39.8\left(\eta_{\mathrm{p}}^{2}\right.$ $\geq 0.14$ is considered a large effect size)], indicating that the differences in levels of freezing to S2 between Groups Vehicle and CHX were greater than those to S1. Analysis of freezing to S2 revealed a significant linear trend across test presentations $\left(F_{(1,23)}\right.$ $=25.9, p<0.001)$, indicating extinction of freezing responses; but no main effect of group nor a trial $\times$ group interaction $(F$ values $<1$ ). By contrast, analysis of freezing to $S 1$ revealed that Group CHX froze significantly less than Group Vehicle $\left(F_{(1,23)}=\right.$ $6.1, p=0.02, d=1.0,95 \% \mathrm{CI}=3.0,35.1)$. There was a significant linear trend in freezing to $S 1\left(F_{(1,23)}=8.2, p<0.01\right)$, but no significant trial $\times$ group interaction $(F<1)$, suggesting that both groups entered the session freezing at different levels and maintained this difference in freezing across the $\mathrm{S} 1$ presentations. These results show a dissociable effect of intra-BLA cycloheximide infusions on consolidation of fear to S2 and S1: these infusions impaired consolidation of the reacquired fear to S1 but had no detectable effect on consolidation of the newly acquired fear to S2.

\section{Experiment 4}

Consolidation of fear to S2 was disrupted by the BLA infusion of cycloheximide when $S 1$ had not been pretrained (Experiment 1) but was unaffected when S1 entered the S2-S1-shock session already fear-conditioned (Experiment $2 \mathrm{a}$ ) or fear-conditioned but extinguished before the S2-S1-shock session (Experiment 3). The present experiment examined whether any type of S1 and/or shock pretraining rendered S2 immune to the disruptive effect of cycloheximide. The experiment arranged that rats received the 
same number of S1 and shock presentations (four of each) as in Experiment 2a, but in an explicitly unpaired fashion (for a schematic, see Fig. $6 a$ ). Rats then received the serial-order conditioning session, followed immediately by intra-BLA infusions of cycloheximide or vehicle. Finally, rats were tested for fear of S2 and $\mathrm{S} 1$ in the counterbalanced order used previously.

Rats exhibited little or no freezing to $S 1$ when presented alone in Stage 1, and there were no significant between-group differences ( $F$ values $<1$; Table 1$)$. Subsequently, both groups successfully developed freezing across the S2-S1-shock conditioning session. There was a significant main effect of trials for freezing to $\mathrm{S} 2\left(F_{(1,27)}=116.1, p<0.001\right)$ and $\mathrm{S} 1\left(F_{(1,27)}=39.9, p<0.001\right)$, but no main effects of group, and no trial $\times$ group interactions for levels of freezing to either S2 or S1 ( $F$ values $<1.5, F c=4.2$, $p>0.23)$.

Figure $6 b$ shows the test levels of freezing to S2 (left) and S1 (right). The statistical analysis confirmed what is clear from inspection of the test data: rats in Group CHX froze significantly less than rats in Group Vehicle across test presentations of both $\mathrm{S} 2\left(F_{(1,27)}=12.8, p<0.01, d=1.4,95 \% \mathrm{CI}=12.4,45.6\right)$ and S1 $\left(F_{(1,27)}=8.6, p<0.01, d=0.8,95 \% \mathrm{CI}=8.6,48.5\right)$. There was a significant main effect of $S 2$ trials $\left(F_{(1,27)}=4.8, p=0.04\right)$, but no trial $\times$ group interaction $(F<1)$, indicating that freezing declined across the test session, and that these levels of freezing declined at an equivalent rate in both groups. There was no main effect of S1 trials $(F<1)$, but a significant trial $\times$ group interaction $\left(F_{(1,27)}=4.8, p=0.04\right)$, indicating that the levels of freezing to $\mathrm{S} 1$ in Group CHX declined at a significantly faster rate than levels of freezing in Group Vehicle. These results parallel those observed in Experiment 1: consolidation of fear to S2 and S1 requires protein synthesis in the BLA when the S2-S1-shock session is preceded by no training or by unpaired presentations of S1 and shock, suggesting that consolidation of de novo fear conditioning of each element of the sequence requires protein synthesis.

\section{Experiment 5}

Consolidation of fear to S2 does not require protein synthesis in the BLA when S1 has been previously conditioned, including when it has been extinguished before S2-S1-shock conditioning (Experiments $2 \mathrm{a}$ and 3 ). The present experiment examined whether S1 must be fear-conditioned to render consolidation of S2 independent of protein synthesis in the BLA. It did so by appetitively conditioning $\mathrm{S} 1$, in which rats received $\mathrm{S} 1$-sucrose pairings. They next received the S2-S1-shock conditioning session that was followed immediately by BLA infusions of cycloheximide or vehicle. Finally, rats were tested for fear of S2 (for a schematic, see Fig. 7a). We omitted testing of S1 because a pilot study revealed low levels of freezing to test presentations of S1 in rats that were appetitively conditioned with $S 1$, exposed to the S2-S1-shock session, and tested with S1 (mean $=17 \%$; SEM = $4 \%)$. Presumably, the prior appetitive conditioning of S1 interfered with its fear conditioning, or the test of S1 elicited contrasting appetitive and aversive memories that interfered with the expression of conditioned freezing (indeed, test presentations of $\mathrm{S} 1$ tended to evoke approach responses to the magazine where sucrose had been previously delivered).

S1-sucrose training was successful: magazine entry rates (index of appetitive conditioning) were greater during S1 presentations relative to the baseline period and did not significantly differ between the two groups (Table 1). This was confirmed by the statistical analysis of the S1-baseline difference scores: there was a significant main effect of days $\left(F_{(1,32)}=52.8, p<0.001\right)$ but
Table 2. Experimental designs used in the present study ${ }^{a}$

\begin{tabular}{|c|c|c|c|}
\hline Experiment & Prior training & Serial order & Test \\
\hline 1 & Context exposure & S2-S1-shock (CHX) & $\begin{array}{l}\text { S2: disrupted } \\
\text { S1: disrupted }\end{array}$ \\
\hline $2 a$ & S1-shock & S2-S1-shock (CHX) & $\begin{array}{l}\text { S2: intact } \\
\text { S1: intact }\end{array}$ \\
\hline $2 b$ & S1-shock & S2-S1-shock (5-AZA) & $\begin{array}{l}\text { S2: disrupted } \\
\text { S1: intact }\end{array}$ \\
\hline 3 & S1-shock; S1 extinction & S2-S1-shock (CHX) & $\begin{array}{l}\text { S2: intact } \\
\text { S1: disrupted }\end{array}$ \\
\hline 4 & S1/shock & S2-S1-shock (CHX) & $\begin{array}{l}\text { S2: disrupted } \\
\text { S1: disrupted }\end{array}$ \\
\hline 5 & S1-sucrose & S2-S1-shock (CHX) & S2: disrupted \\
\hline
\end{tabular}

${ }^{a}$ In each experiment, rats received a BLA infusion of vehicle or drug immediately following serial-order conditioning, except in Experiment 2a, in which rats received a BLA infusion of vehicle or drug either immediately before or after serial-order conditioning. The drug infused was the protein synthesis inhibitor cycloheximide, except for Experiment $2 \mathrm{~b}$, in which the drug infused was the DNA methyltransferase inhibitor 5-AZA. A hyphen (-) indicates a paired relation between stimuli (e.g., S1-shock), whereas a backslash (/) indicates an unpaired relation (e.g., S1/shock).

no main effect of group nor a day $\times$ group interaction $(F$ values $<$ 1). Subsequent to appetitive conditioning of $S 1$, all rats developed freezing across the S2-S1-shock session. There were main effects of trials for freezing to S2 $\left(F_{(1,32)}=154.5, p<0.001\right)$ and $S 1$ $\left(F_{(1,32)}=115.4, p<0.001\right)$ but no effect of groups $(F$ values $<1)$ nor trial $\times$ group interactions $(F$ values $<2.6, F c=4.2, p>0.11)$ for freezing to either S2 or S1.

Figure 7 shows the test levels of freezing to S2. The statistical analysis confirmed what is clear from inspection of the figure: rats in Group Vehicle froze significantly more to S2 than rats in Group CHX $\left(F_{(1,32)}=9.7, p<0.01, d=1.2,95 \% \mathrm{CI}=6.7,32.0\right)$. There was a main effect of trials for freezing to $\mathrm{S} 2\left(F_{(1,32)}=9.7\right.$, $p<0.01, d=1.2,95 \% \mathrm{CI}=6.7,32.0)$, showing that freezing declined across the test presentations, but no trial $\times$ group interaction, indicating that levels of freezing to S2 declined at an equivalent rate in both groups. These results show that the presence of an appetitively conditioned S1 in the S2-S1-shock sequence does not render consolidation of fear to S2 independent of protein synthesis in the BLA. Rather, the critical requirement for this independence is the presence of an S1 that had been fear-conditioned. This result and those reported for the previous experiments are summarized in Table 2.

\section{Discussion}

The present study has shown that the presence of an already-fearconditioned stimulus alters the de novo protein synthesis requirement for consolidating a new fear memory in the BLA. In each experiment, rats received a session of serial-order conditioning in which they were exposed to four S2-S1-shock sequences, followed immediately by a BLA infusion of vehicle or the protein synthesis inhibitor cycloheximide (apart from Experiment 2b, in which they received a BLA infusion of the DNMT inhibitor 5-AZA). Subsequently, they were tested for the levels of freezing elicited by S2 and S1. The experiments differed in the type of training which the rats received before serial-order conditioning. This training consisted of exposure to the conditioning chamber in the absence of any scheduled events (Experiment 1), S1-shock pairings (Experiments 2a and 3), explicitly unpaired presentations of S1 and shock (Experiment 4), or S1-sucrose pairings (Experiment 5).

The BLA infusion of cycloheximide disrupted consolidation of fear to S2 when serial-order conditioning had been preceded by exposure to the conditioning context (Experiment 1), un- 
paired presentations of S1 and shock (Experiment 4), and appetitive conditioning of $S 1$ via its pairings with sucrose (Experiment 5 ). In contrast, the BLA infusion of cycloheximide failed to disrupt consolidation of fear to S2 when serial-order conditioning had been preceded by fear conditioning of S1 via its pairings with shock (Experiment 2a), even when those pairings were followed by $\mathrm{S} 1$ alone presentations to extinguish the conditioned fear (Experiment 3). The failure to disrupt consolidation of fear to S2 was not due to an effect of the prior S1-shock pairings on the timing of the protein synthesis requirement. Experiment 2a found that consolidation of this fear was unaffected when cycloheximide was infused into the BLA before the serial-order conditioning session, thereby precluding the possibility that fear to $\mathrm{S} 2$ was consolidated via proteins synthesized during the conditioning session itself. Importantly, Experiment $2 \mathrm{~b}$ showed that consolidation of fear to S2 required the BLA, as fear to S2 was disrupted when serial-order conditioning was followed by BLA infusion of the DNMT inhibitor 5-AZA. These results indicate that the prior S1-shock pairings changed the role of protein synthesis, but not the role of the BLA, in consolidating fear to $\mathrm{S} 2$. These findings show that, within the BLA, the substrates required for consolidation of the fear that accrues to S2 across the S2-S1-shock sequences is regulated by what has been learned about S1. When S1 was novel, had previously been presented in an unpaired relation to shock, or had previously signaled an appetitive US (sucrose), consolidation of fear to S2 required de novo protein synthesis in the BLA. When S1 had previously signaled the shock US, regardless of whether or not it currently did so, consolidation of fear to S2 required changes in DNA methylation but did not require de novo protein synthesis in the BLA, potentially indicating that patterns of DNA methylation constitute a more fundamental mnemonic substrate (Pearce et al., 2017).

While the prior history of S1 determined whether or not consolidation of fear to S2 required de novo protein synthesis in the BLA, protein synthesis was always required to consolidate fear to S1. Specifically, when serial-order conditioning had been preceded by no pretraining (Experiment 1) or explicitly unpaired presentations of S1 and shock (Experiment 4), consolidation of the fear that accrued to S1 was disrupted by the BLA infusion of cycloheximide. The BLA infusion of cycloheximide also disrupted consolidation when the serial-order conditioned S2 was extinguished and retrained as a first-order CS via its pairings with shock (Experiment 2a), and when S1 had been paired with shock, extinguished and then reconditioned across the S2-S1-shock sequences (Experiment 3). Importantly, in the latter case, the BLA cycloheximide infusion acted selectively to disrupt consolidation of reconditioned fear to S1 while sparing consolidation of fear to S2. These contrasting effects on fear of S2 and S1 show that the differential protein synthesis requirements for their consolidation are present in a within-subjects design. The only exception regarding the disruptive effect of cycloheximide on fear to S1 was in Experiment 2a, where serial-order conditioning was preceded by $\mathrm{S} 1$-shock pairings. In that experiment, the cycloheximide infusion failed to affect the already-consolidated S1-shock association. Presumably, the failure to detect any such effect was due to S1 entering the serial-order conditioning session at asymptote. Alternatively, the failure may have been due to any of the boundary conditions that constrain the circumstances required for destabilizing and reconsolidating associative memories, such as the "strength" of the already-established S1-shock association (Tronson and Taylor, 2007; Wang et al., 2009; Kindt, 2018).

Why does an already-fear-conditioned S1 remove the protein synthesis requirement for consolidating fear to S2? One possibil- ity is that this type of S1 alters what is learned about the S2 in serial-order conditioning. When S1 was novel, had been previously trained in an unpaired relation to shock, or had been previously paired with sucrose, S2 is likely to have associated with the shock US, as it provided an early signal of the forthcoming shock. Hence, just as consolidation of the association produced by CSshock pairings requires protein synthesis in the BLA, consolidation of the fear that accrues to S2 under the conditions just described also requires protein synthesis in the BLA. In contrast, the already-fear-conditioned S1 may have blocked the association between S2 and shock while simultaneously permitting second-order conditioned fear to S2. Previous work in our laboratory has shown that this type of fear does not require de novo protein synthesis in the BLA for its consolidation (Lay et al., 2018). One potential issue for that proposal is that consolidation of fear to S2 remained independent of protein synthesis in the BLA when S1 had been conditioned and extinguished, thus limiting the opportunity for its second-order fear conditioning. However, the delivery of shock during serial-order training would have rapidly reinstated the ability of S1 to elicit fear (Rescorla and Heth, 1975), thereby enabling second-order fear conditioning of S2.

Why might the association produced by fear conditioning (CS-shock or second-order) determine whether or not protein synthesis is required for its consolidation in the BLA? The BLA is a critical site of the plasticity that underlies consolidation of a CS-shock association. For second-order associations, however, it may be that activity in the BLA (including DNA methylation) is required to coordinate changes that occur in other regions of the brain, but is not itself the site of the plasticity that underlies consolidation. At present, very little is known about the broader circuitry that regulates second-order conditioned fear, or the fear that accrues to S2 when it is shocked in compound with an already-fear-conditioned S1 (presumed to be second-order). Among the circuitry that is known to regulate first-order fear, three regions are potential candidate sites for the plasticity that underlies second-order fear. The first is the prelimbic region of the $\mathrm{mPFC}$, which is crucial for the expression of conditioned fear (Burgos-Robles et al., 2009). The second is the central nucleus of the amygdala, which is involved in CS-shock associations (Wilensky et al., 2006; Han et al., 2015) and which may constitute the site of associative formation between S2 and the fear responses elicited by the already-conditioned S1 (Balleine and Killcross, 2006). The third region is the hippocampus, which is involved in assimilating new information (e.g., about the S2) into an existing memory network (Wang and Morris, 2010). Each of these regions plays a significant role in fear learning via their direct connections with the BLA (Pitkänen et al., 2000; Herry et al., 2008; Sah and Westbrook, 2008), and are sites of plasticity and consolidation of CS-shock associations, including the need for kinase signaling and protein synthesis (Wilensky et al., 2006; Gonzalez et al., 2015; Ryan et al., 2015). However, the role of these regions in consolidating second-order fear, and how any such role relates to the ongoing requirement for DNA methylation in the BLA to consolidate fear to S2, remains to be determined.

In conclusion, the present study has shown that the substrates required for consolidating a new fear memory in the BLA depend on what has already been learned about other stimuli that are present. Protein synthesis in the BLA is required to consolidate fear to a new stimulus (S2) that is shocked in compound with a partner (S1) that is novel, had been previously trained in an explicitly unpaired relation to shock, or had been previously paired with sucrose. Protein synthesis in the BLA is not required to 
consolidate fear to a new stimulus that is shocked in compound with a partner that has already been fear-conditioned. These findings strongly suggest that the association produced by fear conditioning determines the protein synthesis requirement for its consolidation in the BLA. The presence of an already-fearconditioned stimulus encourages formation of a second-order fear association, and the BLA may consolidate this type of association by coordinating changes in other components of the neural fear circuit.

\section{References}

Balleine BW, Killcross S (2006) Parallel incentive processing: an integrated view of amygdala function. Trends Neurosci 29:272-279.

Brayton CF (1986) Dimethyl sulfoxide (DMSO): a review. The Cornell Vet 76:61-90.

Burgos-Robles A, Vidal-Gonzalez I, Quirk GJ (2009) Sustained conditioned responses in prelimbic prefrontal neurons are correlated with fear expression and extinction failure. J Neurosci 29:8474-8482.

Davis M (1992) The role of the amygdala in fear and anxiety. Annu Rev Neurosci 15:353-375.

Duvarci S, Nader K, LeDoux JE (2005) Activation of extracellular signalregulated kinase-mitogen-activated protein kinase cascade in the amygdala is required for memory reconsolidation of auditory fear conditioning. Eur J Neurosci 21:283-289.

Fanselow MS (1980) Conditional and unconditional components of postshock freezing. Pavlovian J Biol Sci 15:177-182.

Fanselow MS (1998) Pavlovian conditioning, negative feedback, and blocking: mechanisms that regulate association formation. Neuron 20:625627.

Gewirtz JC, Davis M (1997) Second-order fear conditioning prevented by blocking NMDA receptors in amygdala. Nature 388:471-474.

Gonzalez MC, Villar ME, Igaz LM, Viola H, Medina JH (2015) Dorsal medial prefrontal cortex contributes to conditioned taste aversion memory consolidation and retrieval. Neurobiol Learn Mem 126:1-6.

Han S, Soleiman MT, Soden ME, Zweifel LS, Palmiter RD (2015) Elucidating an affective pain circuit that creates a threat memory. Cell 162:363374.

Herry C, Ciocchi S, Senn V, Demmou L, Müller C, Lüthi A (2008) Switching on and off fear by distinct neuronal circuits. Nature 454:600-606.

Holmes NM, Parkes SL, Killcross AS, Westbrook RF (2013) The basolateral amygdala is critical for learning about neutral stimuli in the presence of danger, and the perirhinal cortex is critical in the absence of danger. J Neurosci 33:13112-13125.

Holmes NM, Cai SY, Lay BP, Watts NR, Westbrook RF (2014) Extinguished second-order conditioned fear responses are renewed but not reinstated. J Exp Psychol Anim Learn Cogn 40:440-456.

Kindt M (2018) The surprising subtleties of changing fear memory: a challenge for translational science. Philos Trans R Soc Lond B Biol Sci 373:20170033.

Lay BP, Westbrook RF, Glanzman DL, Holmes NM (2018) Commonalities and differences in the substrates underlying consolidation of first-and second-order conditioned fear. J Neurosci 38:1926-1941.

Leidl DM, Lay BP, Chakouch C, Westbrook RF, Holmes NM (2018) Protein synthesis in the basolateral amygdala complex is required for consolidation of a first-order fear memory, but not for consolidation of a higherorder fear memory. Neurobiol Learn Mem 153:153-165.

Maddox SA, Watts CS, Schafe GE (2014) DNA methyltransferase activity is required for memory-related neural plasticity in the lateral amygdala. Neurobiol Learn Mem 107:93-100.

McNally GP, Westbrook RF (2006) Predicting danger: the nature, consequences, and neural mechanisms of predictive fear learning. Learn Mem 13:245-253.

Miller S, Yasuda M, Coats JK, Jones Y, Martone ME, Mayford M (2002) Disruption of dendritic translation of CaMKII $\alpha$ impairs stabilization of synaptic plasticity and memory consolidation. Neuron 36:507-519.

Monsey MS, Ota KT, Akingbade IF, Hong ES, Schafe GE (2011) Epigenetic alterations are critical for fear memory consolidation and synaptic plasticity in the lateral amygdala. PLoS One 6:e19958.

Parkes SL, Westbrook RF (2010) The basolateral amygdala is critical for the acquisition and extinction of associations between a neutral stimulus and a learned danger signal but not between two neutral stimuli. J Neurosci 30:12608-12618.

Pavlov I (1927) Conditioned reflexes: an investigation of the physiological activity. Oxford, UK: Oxford UP.

Paxinos G, Watson, C (1997) The rat brain atlas in stereotaxic coordinates, compact. San Diego: Academic.

Paxinos G, Watson C (2007) The rat brain in stereotaxic coordinates. San Diego: Academic.

Pearce K, Cai D, Roberts AC, Glanzman DL (2017) Role of protein synthesis and DNA methylation in the consolidation and maintenance of longterm memory in Aplysia. eLife 6:e18299.

Pitkänen A, Pikkarainen M, Nurminen N, Ylinen A (2000) Reciprocal connections between the amygdala and the hippocampal formation, perirhinal cortex, and postrhinal cortex in rat: a review. Ann N Y Acad Sci 911:369-391.

Rescorla RA, Heth CD (1975) Reinstatement of fear to an extinguished conditioned stimulus. J Exp Psychol Anim Behav Process 1:88-96.

Rizley RC, Rescorla RA (1972) Associations in second-order conditioning and sensory preconditioning. J Comp Physiol Psychol 81:1-11.

Ryan TJ, Roy DS, Pignatelli M, Arons A, Tonegawa S (2015) Engram cells retain memory under retrograde amnesia. Science 348:1007-1013.

Sah P, Westbrook RF (2008) Behavioural neuroscience: the circuit of fear. Nature 454:589-590.

Schafe GE, Nadel NV, Sullivan GM, Harris A, LeDoux JE (1999) Memory consolidation for contextual and auditory fear conditioning is dependent on protein synthesis, PKA, and MAP kinase. Learn Mem 6:97-110.

Schneider-Poetsch T, Ju J, Eyler DE, Dang Y, Bhat S, Merrick WC, Green R, Shen B, Liu JO (2010) Inhibition of eukaryotic translation elongation by cycloheximide and lactimidomycin. Nat Chem Biol 6:209-217.

Tronson NC, Taylor JR (2007) Molecular mechanisms of memory reconsolidation. Nat Rev Neurosci 8:262-275.

Wang SH, de Oliveira Alvares L, Nader K (2009) Cellular and systems mechanisms of memory strength as a constraint on auditory fear reconsolidation. Nat Neurosci 12:905-912.

Wang SH, Morris RG (2010) Hippocampal-neocortical interactions in memory formation, consolidation, and reconsolidation. Annu Rev Psychol 61:49-79, C1-C4.

Wilensky AE, Schafe GE, Kristensen MP, LeDoux JE (2006) Rethinking the fear circuit: the central nucleus of the amygdala is required for the acquisition, consolidation, and expression of Pavlovian fear conditioning. J Neurosci 26:12387-12396.

Witnauer JE, Miller RR (2011) Some determinants of second-order conditioning. Learn Behav 39:12-26.

Yin H, Barnet RC, Miller RR (1994) Second-order conditioning and Pavlovian conditioned inhibition: operational similarities and differences. J Exp Psychol Anim Behav Process 20:419-428. 